\title{
Efficiency of Coir Particle Board for Acoustic \& Thermal Applications
}

\author{
M. C. Kiran, B. S. Mamatha, N. Anand, V. Prakash, Narasimha Murthy \\ IPIRTI, Tumkur Road, Bangalore, Karnataka, India \\ Email: kiranraogadekar@gmail.com, mamatha@ipirti.gov.in, anandn@ipirti.gov.in, prakash77v@gmail.com, \\ nmurthy@ipirti.gov.in
}

How to cite this paper: Kiran, M.C., Mamatha, B.S., Anand, N., Prakash, V. and Murthy, N. (2019) Efficiency of Coir Particle Board for Acoustic \& Thermal Applications. Open Journal of Acoustics, 9, 39-47

https://doi.org/10.4236/oja.2019.93004

Received: August 26, 2019

Accepted: September 27, 2019

Published: September 30, 2019

Copyright (c) 2019 by author(s) and Scientific Research Publishing Inc. This work is licensed under the Creative Commons Attribution International License (CC BY 4.0).

http://creativecommons.org/licenses/by/4.0/

\begin{abstract}
Coir fibre is extracted from the husk of coconut and is used in products such as floor mats, door mats, brushes and mattresses and in many applications. Here coir fibres are used to make particle boards of densities 300, 400 and 500 $\mathrm{kg} / \mathrm{m}^{3}$ using UF resin to determine its efficiency for interior applications like acoustic and thermal properties and also tested for Indian standard 3129. Noise Reduction Coefficient (NRC) of all the boards decreases with an increase in density. Maximum sound absorption coefficient for all three densities was found in the frequency range of 2500 to $30,000 \mathrm{~Hz}$. Among three densities, $300 \mathrm{~kg} / \mathrm{m}^{3}$ board shows the maximum absorption coefficient at frequency $3000 \mathrm{~Hz}$. The thermal conductivity results of all three densities boards increase with an increase in density. Modulus of Rupture for all three densities were meeting the requirement of standard. Results reveal that particle board manufactured from coir fibre can be used for acoustic and thermal insulation applications.
\end{abstract}

\section{Keywords}

Thermal Conductivity, Sound Absorption Coefficient

\section{Introduction}

From ancient time, natural fiber material is used for day to day applications and in the recent inventions, it is also noticed that fibre composite materials can be used in building \& furniture applications also [1]. Due to the light weight, high strength to weight ratio, corrosion resistance and other advantages, natural fibre-based composites are becoming important composite materials in construction field in case of synthetic fibre-based composites, despite the usefulness in service, these are difficult to be recycled after designed service life. However, 
natural fibre-based composites are environment friendly to a great extent.

Flax board has less hygroscopicity than solid timber and wooden chipboard. Linear thickness swelling in water, however, with the density classes $0.60 \mathrm{~g} / \mathrm{cm}^{3}$ and $0.65 \mathrm{~g} / \mathrm{cm}^{3}$ as well as water absorption are a little greater than in the case of wooden chipboard [2]. Rice-straw particle boards with density of 0.4 and 0.6 $\mathrm{gr} / \mathrm{cm}^{3}$ have high sound absorption coefficient [3]. Boards made from bagasse with a density of $190 \mathrm{~kg} / \mathrm{m}^{3} \& 370 \mathrm{~kg} / \mathrm{m}^{3}$ have better sound absorption. Depith Bagasse Particle Board can be used as an alternative to synthetic-based commercial products for acoustic applications in building construction [4] [5]. Wheat straw can be used as a promising raw material for panel production with the use of a tannin-modified PF adhesive [6]. Sound transmission loss and sound transmission class values of medium density bamboo particle board of $800 \mathrm{~kg} / \mathrm{m}^{3}$ were better than the low density bamboo particle board, i.e. higher the density, higher the sound transmission.

In past decade there have been many efforts to develop composites to replace the petroleum and other non-decaying materials-based products. The abundant availability of natural fibre in India gives attention to the development of natural fibre composites primarily to explore value-added application avenues. Reinforcement with natural fibre in composites has recently gained attention due to low cost, easy availability, low density, acceptable specific properties, ease of separation, enhanced energy recovery, $\mathrm{CO}_{2}$ neutrality, biodegradability and recyclable in nature.

In the present scenario, technical progress in manufacturing the modern equipment, generating higher sound pressure, implies the need to search for new sound absorbing materials to improve the human comfort [7]. Composite materials from lignocellulosic fillers can be recommended for application in building industry because of their good sound absorptive power [7].

Agricultural wastes can be used to prepare fibre reinforced polymer composites for commercial use. Although glass and other synthetic fibre-reinforced plastics possess high specific strength, their fields of application are very limited because of their inherent higher cost of production. Large amount of agro wastes are produced annually world over. If left unattended, these wastes occupy fertile, useful lands and possess serious environmental and health problems like water contamination by leaching, bad odour, microbial growths etc. Generally, they are burned in the field itself resulting in increased amount of greenhouse gases. The use of sustainable materials is now becoming a common practice for the noise and heat transfer reduction in construction and civil engineering due to the increasing health risk concern associated with materials such as glass and mineral fibre [8].

India produces $1.60 \mathrm{Mt} / \mathrm{yr}$ of coconut husk and is largely used in manufacture of building boards, roofing sheets, insulation boards, building panels, as a lightweight aggregate, coir fibre reinforced composite, cement board, geo-textile, rubberized coir [1]. Coir is a strong fibre compared to other agro residues like wheat straw, rice straw, bagasse etc; Efforts were made to make low density particle board from coir fibre to determine the efficiency of coir fibre as a sound 
absorbing material and for thermal applications.

\section{Materials and Methods}

Coir was procured from coir board, Peenya has a specific gravity of 0.55 with a moisture content of $10 \%$. Coir of length $2-3 \mathrm{~mm}$ available was used as it is for the manufacture of board. The particles were dried in Hot Air Oven at $62^{\circ} \mathrm{C} \pm$ $2^{\circ} \mathrm{C}$ to get requisite moisture content of $3 \%$ to $4 \%$. Melamine Urea formaldehyde resin (MUF) synthesized at in-house laboratory was used for preparation of low density coir particle board. MUF resin with 1:1 weight ratio of urea and melamine were synthesized at $\mathrm{pH} 8.5$ and at $85^{\circ} \mathrm{C}$ till getting water tolerance of 1:4. The properties of the resin used for the manufacture of particle board are as shown in Table 1.

\subsection{Manufacturing Process of Particle Board}

Sixteen sets of single layered Coir particle boards of dimension $300 \mathrm{~mm} \times 300$ $\mathrm{mm} \times 12 \mathrm{~mm}$ for a targeted density of $300 \mathrm{~kg} / \mathrm{m}^{3}, 400 \mathrm{~kg} / \mathrm{m}^{3}$ and $500 \mathrm{~kg} / \mathrm{m}^{3}$ were manufactured using MUF resin adhesive. The adhesive formulation having Ammonium chloride hardener $(0.4 \%)$ and wax emulsion (1\%) on the liquid resin was made. The particles were blended with $10 \%$ MUF adhesive on dry solid basis. The glue blended particles were placed into a mat forming box with base dimensions of $330 \mathrm{~mm} \times 330 \mathrm{~mm}$. The formulations for the manufacturing of boards are as shown in Table 2. Prepressing and compression of the particles were done by pressing a matching wooden plate on the mat in the forming box by applying manual pressure. Supporting rods to control the thickness to $12 \mathrm{~mm}$ were placed on either ends of the assembly. The assembly was then loaded into a hot press of size $350 \mathrm{~mm} \times 350 \mathrm{~mm}$ wherein temperature of the platens was

Table 1. Properties of MUF Resin.

\begin{tabular}{ccc}
\hline SI No. & Particulars & Results \\
\hline 1. & PH of resin & $8.5-8.83$ \\
2. & Flow time of resin in B4 cup & 18 seconds \\
3. & Water tolerance & $1: 2.5$ \\
4. & Solid content & $50.8 \%$ \\
5. & Gelation time & 180 seconds \\
6. & Shelf life & One month \\
\hline
\end{tabular}

Table 2. Formulations of boards.

\begin{tabular}{cccc}
\hline & $300 \mathrm{~kg} / \mathrm{m}^{3}$ & $400 \mathrm{~kg} / \mathrm{m}^{3}$ & $500 \mathrm{~kg} / \mathrm{m}^{3}$ \\
\hline Particles (g) & 290 & 400 & 500 \\
Resin solids (g) & 29 & 40 & 50 \\
\hline
\end{tabular}


maintained at $160^{\circ} \mathrm{C}$ for particle board. Pressure of $20 \mathrm{~kg} / \mathrm{cm}^{2}$ for compression cycle and $12 \mathrm{~kg} / \mathrm{cm}^{2}$ for curing cycle with requisite curing time for respective resin systems were employed. The boards were kept for stabilization for about 24 48 hours to attain equilibrium moisture content and then trimmed. The trimmed boards were further dimensioned to required sizes and subjected for testing as per relevant specifications.

\subsection{Testing of Boards}

All the test specimens were exposed to an atmosphere maintained at a relative humidity of $65 \pm 5 \% \mathrm{t}$ and at a temperature of $27^{\circ} \mathrm{C} \pm 2^{\circ} \mathrm{C}$ until their masses are nearly constant. The test specimens were kept in this controlled atmosphere until they are required for testing.

Physical properties of the boards viz; Moisture content, swelling due to surface absorption \& water absorption ( $2 \mathrm{~h}$ ) were tested as per IS: 2380 (Methods of test for wood particle boards and boards from other lignocellulosic materials) and compared with values prescribed in IS: 3129 (Specification for Low Density Particle Boards).

Modulus of Rupture the mechanical property carried out in UTM (Universal testing machine) available at the in-house laboratory as per Indian Standard 2380 and compared with Indian Standard 3129.

Sound absorption coefficient was calculated by the method as per IS: 10420-1982 (Determination of sound absorption coefficient of timber by standing wave method) using acoustic Pulse tester available at in-house laboratory. Three sets of samples of diameters $100 \mathrm{~mm}$ and $30 \mathrm{~mm}$ were prepared for studying acoustic properties for frequencies ranging from $125 \mathrm{~Hz}$ to $1500 \mathrm{~Hz}$ and $1500 \mathrm{~Hz}$ to $5000 \mathrm{~Hz}$ respectively. The sound absorption coefficient of the samples was recorded. The average values of three sets were noted for all the three $\left(300,400 \& 500 \mathrm{~kg} / \mathrm{m}^{3}\right)$ density samples. The noise reduction coefficient (NRC) was also calculated as the average of the absorption coefficients at 250, 500, 1000 and $2000 \mathrm{~Hz}$ frequencies.

Thermal conductivity of the samples was determined by the method specified in IS 3346 (Method of the determination of thermal conductivity of thermal insulation materials) using thermal conductivity apparatus in our own laboratory procured from M/s PRAVAK Cybernetics (P) Ltd. which works on the principle of guarded hot plate method and uses an absolute method for the determination of thermal conductivity. Considering the Indian extreme conditions at summer season, the temperature of hot plate and cold plate were set at $50^{\circ} \mathrm{C}$ and $30^{\circ} \mathrm{C}$ respectively for determining thermal conductivity of manufactured boards. Three sets of samples from all three densities $\left(300,400 \& 500 \mathrm{~kg} / \mathrm{m}^{3}\right)$ of cross sectional area $300 \times 300 \mathrm{~mm}$ were prepared to determine thermal conductivity. The thermal conductivity of samples was recorded after steady state condition was observed and the temperature differential between the guarded metered hot plate and the primary guard as well as the auxiliary cold plate was within $0.5^{\circ} \mathrm{C}$. Also, this difference was stable for four consecutive periods of half an hour each. 
During testing of samples, readings were taken only after steady state condition.

The thermal conductivity is computed by the equation as given below:

$$
k=\frac{Q D}{\{A(\Delta T)\}}, \text { in } \mathrm{W} / \mathrm{m}-\mathrm{K}
$$

where:

$Q$ is the heat supplied through a medium, in W.

$A$ is the cross-section of the sample, in $\mathrm{m}^{2}$.

$\Delta T$ is the temperature differential across the medium, in $\mathrm{K}$.

$D$ is the length of the medium through which heat flows (thickness of sample), in $\mathrm{m}$.

$k$ is the thermal conductivity of the medium, $\mathrm{W} / \mathrm{m}-\mathrm{K}$.

\section{Results and Discussion}

The average density of the coir particle boards manufactured was found to be $299 \mathrm{~kg} / \mathrm{m}^{3}, 410 \mathrm{~kg} / \mathrm{m}^{3}$ and $502 \mathrm{~kg} / \mathrm{m}^{3}$ respectively. The Moisture content, MOR and thickness swelling due to surface absorption values are reflected in Table 3. The average Moisture content values were found to be $7.01 \%, 6.87 \%$ \& $6.91 \%$ for the three targeted density boards of $300,400,500 \mathrm{~kg} / \mathrm{m}^{3}$ respectively. MOR value for all densities was meeting the requisite value of Indian standard (IS) 3129. Swelling due to surface absorption of $400 \& 500 \mathrm{~kg} / \mathrm{m}^{3}$ boards was conforming to the requirement and $300 \mathrm{~kg} / \mathrm{m}^{3}$ board was showing little higher thickness swelling. Generally, there will be more space available for the water to move in a lower density particle board due to the low compaction ratio but water absorption results show that all samples after testing were in intact position and no any sign of disintegration or splitting at the edges.

Table 3. Average test results of Moisture content, MOR and Swelling due to surface absorption with standard deviation and coefficient of variation.

\begin{tabular}{|c|c|c|c|c|c|}
\hline \multirow{2}{*}{ SI No } & \multirow{2}{*}{ Properties } & \multirow{2}{*}{$\begin{array}{l}\text { Prescribed Value as } \\
\text { Per IS: } 3129-1985\end{array}$} & \multirow{2}{*}{\multicolumn{3}{|c|}{$\begin{array}{ccc}\text { A } & \text { B } & \text { C } \\
\left(300 \mathrm{~kg} / \mathrm{m}^{3}\right) & \left(400 \mathrm{~kg} / \mathrm{m}^{3}\right)\left(500 \mathrm{~kg} / \mathrm{m}^{3}\right)\end{array}$}} \\
\hline & & & & & \\
\hline \multirow{3}{*}{1} & Moisture content, \% & $\operatorname{Max} 16$ & 7.01 & 6.87 & 6.91 \\
\hline & Standard Deviation & & 0.18 & 0.2 & 0.3 \\
\hline & Coefficient of Variation & & 2.38 & 2.81 & 2.17 \\
\hline \multirow{3}{*}{2} & Modulus of rupture $\left(\mathrm{N} / \mathrm{mm}^{2}\right)$ & Min 1.5 & 2.54 & 6.97 & 13.9 \\
\hline & Standard Deviation & & 0.5 & 0.2 & 0.9 \\
\hline & Coefficient of Variation & & 20.6 & 2.2 & 5.5 \\
\hline \multirow{3}{*}{3} & $\begin{array}{l}\text { Swelling due to surface absorption } \\
\text { (after } 2 \text { hours soaking) } \%\end{array}$ & Max 5 & 6.84 & 4.88 & 4.01 \\
\hline & Standard Deviation & & 1.213 & 0.316 & 0.818 \\
\hline & Coefficient of Variation & & 11 & 3.82 & 4.65 \\
\hline 4 & Water absorption & $\begin{array}{c}\text { No Splitting/ } \\
\text { No disintegration }\end{array}$ & \multicolumn{3}{|c|}{$\begin{array}{l}\text { No splitting at edges \& } \\
\text { No sign of disintegration }\end{array}$} \\
\hline
\end{tabular}


The absorption coefficient is a common quantity used for measuring the sound absorption of a material and is known to be the function of the frequency of the incident wave. It is defined as the ratio of energy absorbed by a material to the energy incident upon its surface. Sound absorption coefficient of all three densities boards was measured till $5000 \mathrm{~Hz}$. Figure 1 shows the Sound absorption coefficient of all three density boards. Table 4 indicates the Average values of Thermal conductivity with Standard deviation and coefficient of variation. From Figure 1, it can be seen that the values of all three boards increased with increase in frequency up to $3000 \mathrm{~Hz}$ and gradually the values decreased for higher frequencies starting from $3500 \mathrm{~Hz}$ to $5000 \mathrm{~Hz}$. This increase and decrease were due to the specific characteristic of coir material. As the frequency increases above $3000 \mathrm{~Hz}$, sound absorption decreases, a porous material which allow the passage of the wave with greater or lesser efficiency sound absorption. The porosity of any panel depends on the raw material used, density of the composite and also the empty spaces between them, which opposes the air pressure caused by the sound wave. $300 \mathrm{~kg} / \mathrm{m}^{3}$ shows a higher absorption of 0.80 at $3000 \mathrm{~Hz}$ and gives the best absorption compared to other two boards B $400 \mathrm{~kg} / \mathrm{m}^{3}$ \& C 500 $\mathrm{kg} / \mathrm{m}^{3}$. Standard deviation and Coefficient of variation shows there is no much significant variation between the set of samples results.

Noise Reduction Coefficient (NRC) is an average rating of how much sound an acoustic board can absorb. It is the average values of absorption coefficients for a specific material at the octave band center frequencies of 250, 500, 1000 and $2000 \mathrm{~Hz}$. Noise reduction coefficients (NRC) of three density boards calculated were $0.29,0.26$ and 0.24 all the three values are comparable with NRC values of wadding material (30 mm thick, 0.31), Fiber board (25 mm thick, 0.258) and wood wool building slab (25 mm thick, 0.3) [9]. From Figure 2, NRC values decrease with an increase in density and follow linear trend line equation $y=$ $-0.0003 x+0.3633$ with coefficient of determination $0.9868\left(\mathrm{R}^{2}\right)$.

As shown in Figure 3, at a density of 300,400 and $500 \mathrm{~kg} / \mathrm{m}^{3}$, the $k$ values of the boards were $0.120,0.140$ and $0.170 \mathrm{~W} / \mathrm{mK}$, respectively. Thermal conductivity of coir boards varies from 0.120 to $0.169 \mathrm{~W} / \mathrm{m}-\mathrm{K}$ for density range 300 to 500 $\mathrm{kg} / \mathrm{m}^{3}$. Table 4 shows thermal conductivity values of all three density coir boards with standard deviation and coefficient of variation. The effect of density on thermal conductivity of coir boards is as shown in Figure 3. Thermal conductivity

Table 4. Average values of Thermal conductivity with Standard deviation and coefficient of variation.

\begin{tabular}{cccccc}
\hline \multirow{2}{*}{ SI No } & \multirow{2}{*}{ Sample } & Density $\left(\mathrm{kg} / \mathrm{m}^{3}\right)$ & \multicolumn{2}{c}{ Thermal Conductivity $(\mathrm{W} / \mathrm{m}-\mathrm{K})$} \\
\cline { 4 - 5 } & & $300\left(\mathrm{~kg} / \mathrm{m}^{3}\right)$ & $400\left(\mathrm{~kg} / \mathrm{m}^{3}\right)$ & $500\left(\mathrm{~kg} / \mathrm{m}^{3}\right)$ \\
\hline \multirow{3}{*}{1} & Average & $\mathbf{0 . 1 2 0}$ & $\mathbf{0 . 1 3 8}$ & $\mathbf{0 . 1 6 9}$ \\
& \multirow{2}{*}{ Coir PB } & Standard Deviation & 0.006 & 0.004 & 0.005 \\
& & Coefficient of Variation & 0.051 & 0.032 & 0.027 \\
\hline
\end{tabular}




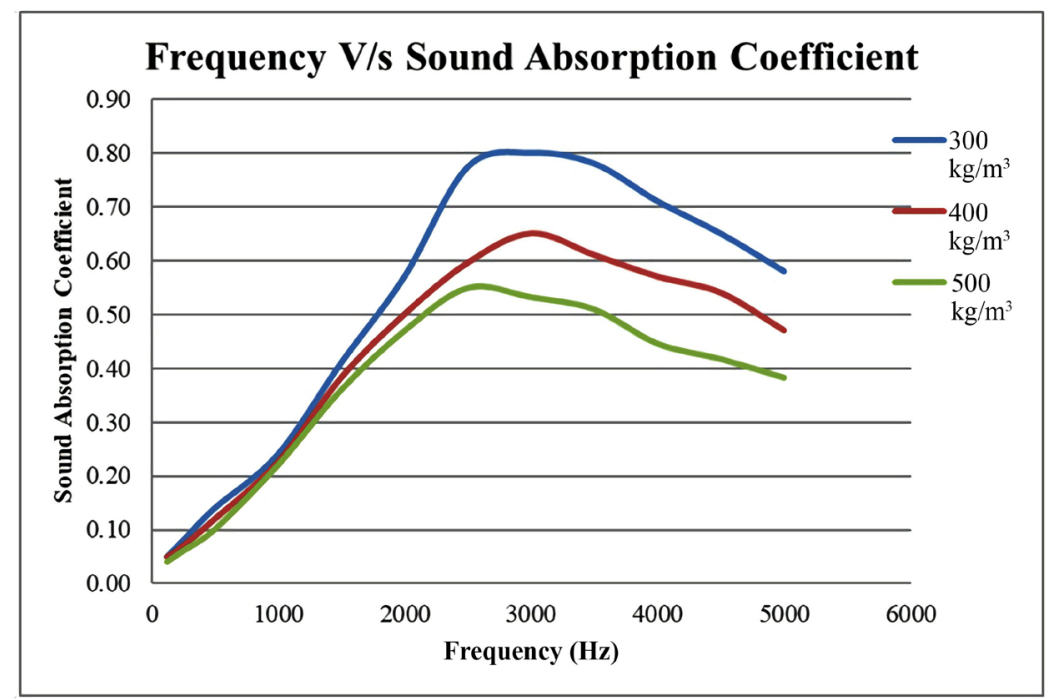

Figure 1. Sound absorption coefficient of all three density boards.

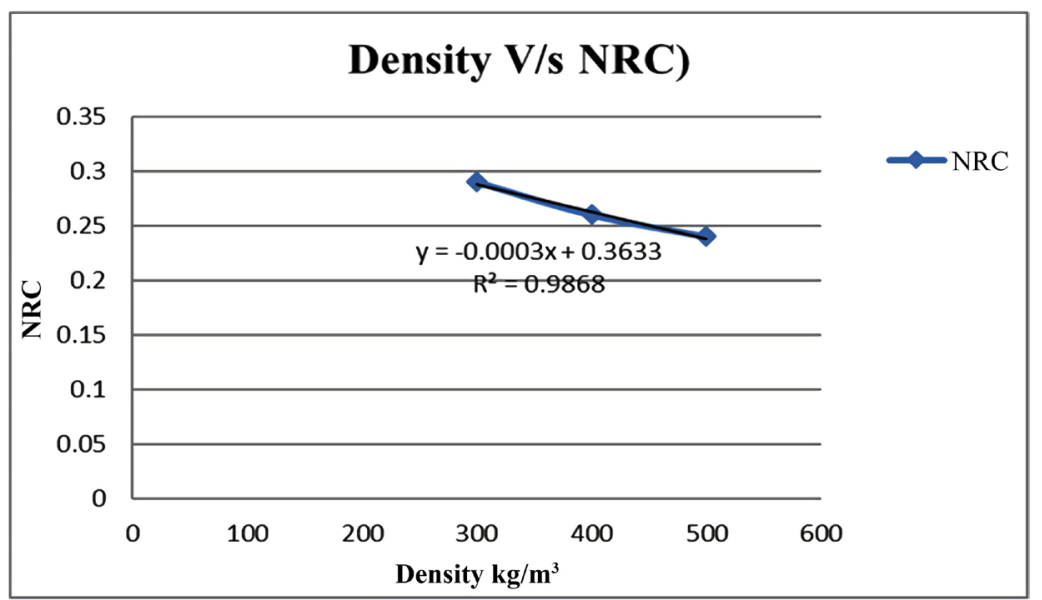

Figure 2. Density versus noise reduction coefficient with linear trend equation and coefficient of Determination $\left(\mathrm{R}^{2}\right)$.

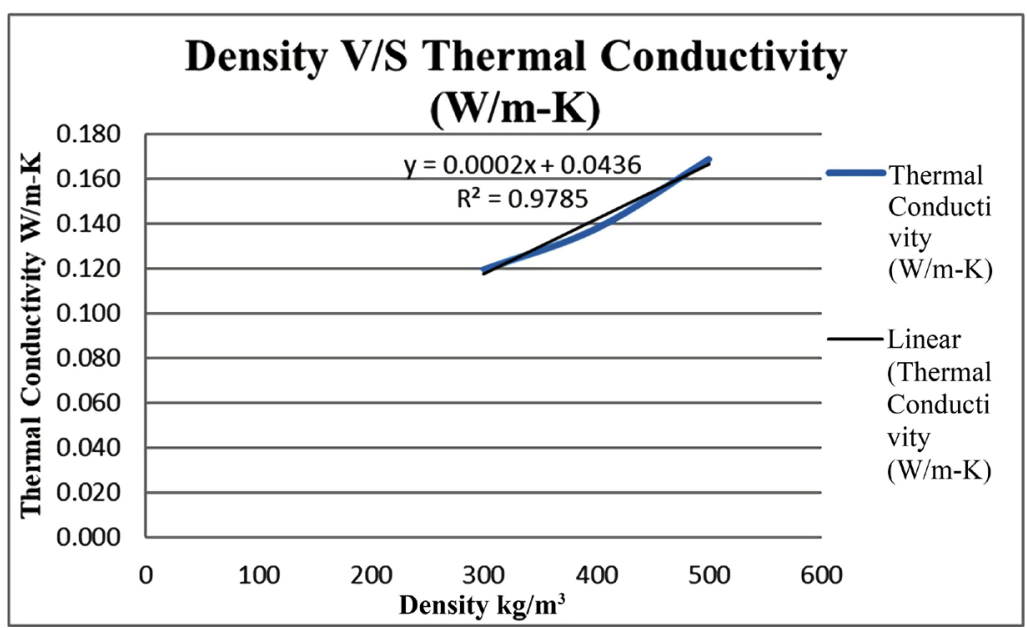

Figure 3. Density versus thermal conductivity with linear trend equation and coefficient of determination $\left(\mathrm{R}^{2}\right)$. 
increases as the density of the board increases and follows linear trend line relationship $y=0.0002 x+0.0436$ with coefficient of determination $0.9785\left(\mathrm{R}^{2}\right)$.

It is seen that the thermal conductivity values are directly related to the density of the board, the highest density boards having the least insulating effect. This is due to the fact that the low-density board contains a large number of voids filled with air, which is one of the poorest conductors [10]. Thus the lower density boards conduct less heat than the higher density boards.

Note that, materials with the thermal conductivity less than $0.25 \mathrm{~W} / \mathrm{mK}$ are generally seen as thermal insulations [10]. Therefore, it can be concluded that the coir particleboards are excellent materials for thermal insulators. The material is comparable with other materials such as coffee husk and hulls boards of $(0.110 \mathrm{~W} / \mathrm{mK})[11]$, lightweight concrete $(0.155 \mathrm{~W} / \mathrm{mK})$ [12].

\section{Conclusion}

Experiment illustrates that particle board made from coir fiber particles can be used in acoustic application as sound absorbent material. Density of board 400 $\mathrm{kg} / \mathrm{m}^{3}$ conforms all requirements of IS-3129 with better MOR and indicates that it can also take loads as prescribed in Indian standard 3129 for low density application. Particle boards with densities $400 \mathrm{~kg} / \mathrm{m}^{3} \& 500 \mathrm{~kg} / \mathrm{m}^{3}$ conform to the requirement of swelling due to surface absorption as per IS 3129. With an increase in density, thermal conductivity also increases and coir particle boards can also be used for heat sink applications. Still the scope of applications can be extended by mixing other agro residues waste with coir to know how best it performs as insulator for thermal and acoustic applications.

\section{Acknowledgements}

The authors would like to sincerely thank to Director, IPIRTI-Bangalore for providing necessary research facilities and timely support.

\section{Conflicts of Interest}

The authors declare no conflicts of interest regarding the publication of this paper.

\section{References}

[1] Verma, D., Gope, P.C., Shandilyal, A., Guptal, A. and Maheshwari, M.K. (2013) Coir Fibre Reinforcement and Application in Polymer Composites: A Review. Journal of Materials and Environmental Science, 4, 263-276.

[2] Lawniezak, M. and Zielinshes, S. (1961) Mechanical and Technological Properties of Flaxboard. Holz als Roh- und Werkstoff, 19, 232-239. https://doi.org/10.1007/BF02612519

[3] Yang, H, Kim, D.-J. and Kim, H.-J. (2003) Rice Straw-Wood Particle Composite for Sound Absorbing Wooden Construction Materials. Journal of Bioresource Technology, 86, 117-121. https://doi.org/10.1016/S0960-8524(02)00163-3

[4] Mamatha, B.S., Nandanwar, A., Sujatha, D., Uday, D.N. and Kiran, M.C. (2014) Particle Board from Bagasse for Acoustic Panel. International Journal of Fundamental Applied Science, 3, 42-44. 
[5] Tabarsaa, T., Jahanshahia, S. and Ashorib, A. (2011) Mechanical and Physical Properties of Wheat Straw Boards Bonded with a Tannin Modified Phenol-Formaldehyde Adhesive. Journal of Composites Part B: Engineering, 42, 176-180. https://doi.org/10.1016/j.compositesb.2010.09.012

[6] Karlinasari, L. and Hermawan, D. (2012) Acoustical Properties of Particle Boards Made from Betung Bamboo (Dendrocalamus asper) as Building Constructional Material. Journal of Bioresource Technology, 7, 5700-5709.

https://doi.org/10.15376/biores.7.4.5700-5709

[7] Markiewicz, E., Paukszta, D. and Borysiak, S. (2012) Acoustic and Dielectric Properties of Polypropylene-Lignocellulosic Materials Composites. In: Polypropylene, Chapter 12, InTech, London, 193-216.

[8] Fatima, S. and Mohanty, A.R. (2011) Acoustical and Fire-Retardant Properties of Jute Composite Materials. Journal of Applied Acoustics, 72, 108-114.

https://doi.org/10.1016/j.apacoust.2010.10.005

[9] Nandanwar, A., Kiran, M.C. and Varadarajulu, K.C. (2017) Influence of Density on Sound Absorption Coefficient of Fibre Board. Open Journal of Acoustics, 7, 1-9. https://doi.org/10.4236/oja.2017.71001

[10] Zhou, X.Y., Zheng, F., Li, H.G. and Lu, C.L. (2010) An Environment-Friendly Thermal Insulation Material from Cotton Stalk Fibers. Energy and Buildings, 42, 1070-1074. https://doi.org/10.1016/j.enbuild.2010.01.020

[11] Bekalo, S.A. and Reinhardt, H.W. (2010) Fibers of Coffee Husk and Hulls for the Production of Particleboard. Materials and Structures, 43, 1049-1960. https://doi.org/10.1617/s11527-009-9565-0

[12] Al-Ajlan, S.A. (2006) Measurements of Thermal Properties of Insulation Materials by Using Transient Plane Source Technique. Applied Thermal Engineering, 26, 2184-2191. https://doi.org/10.1016/j.applthermaleng.2006.04.006 